\title{
O EXEMPLO DA CERA: IMAGINAÇĂO E ENTENDIMENTO EM DESCARTES
}

Loraine Oliveira*

SÍNTESE - A partir do exemplo da cera, na Segunda Meditação, Descartes demonstra a diferença entre os conceitos de imaginação e entendimento, para responder à questão sobre o que se conhece da cera com tanta distinção, a qual em última análise é: o que conheço de mim com tanta distinção? Para saber o que conhece, é preciso saber através de qual faculdade conhe$\mathrm{ce}$, se pela imaginação, ou pelo entendimento. Com o objetivo de chegar a tais conceitos, serão vistos os termos compreensão e concepção nas versões latina e francesa das Meditaçōes. Por fim, se concluirá que o conhecimento não se dá pela imaginação, mas sim pelo entendimento.
ABSTRACT - Starting from the example of wax, in the Second Meditation, Descartes demonstrates the difference between the concepts of imagination and understanding, aiming to give an answer to the following question: what do I know about me with so much a great distinction? In order to know what we know, it is necessary to know the faculty by means of which occurs the understanding. There are two possibilities: either by the imagination or by the understanding. Two words, namely comprehension and conception, in their Latin and French versions, will be examinated, in order to obtain such concepts. Finally, the conclusion will be that knowledge occurs by means of understanding

Descartes, na Segunda Meditação, apresenta sua conhecida afirmação "eu sou, eu existo" (ego sum, ego existo) e, após saber que é, resta-lhe saber o que é. Conclui, então, que é pelo entendimento que se pode conceber de fato o que é alguma coisa e não pela imaginação. A diferença entre os dois conceitos tenta demonstrá-la através do exemplo da cera.

"Commençons par la considération des choses les plus communes, et que nous croyons comprendre le plus distinctement, à savoir, les corps que nous touchons et que nous voyons. [...] Prenons pour exemple ce morceau de cire qui vient d'être tiré de la ruche: il n'a pas encore perdu de la douceur du miel qu'il contenait, il retient encore quelque chose de l'odeur des fleurs dont il a été recueilli; sa couleur, sa figure, sa grandeur, sont apparentes; il est dur, il est froid, on le touche, et si vous le frappez, il rendra quelque son. Enfin toutes les choses qui peuvent distinctement faire connaître un corps, se rencontrent en celui-ci.

* Mestre em Filosofia pela PuCRs. 
"Mais voici que, cependant que je parle, on l'approche du feu: ce qui y restait de saveur s'exhale, l'odeur s'évanouit, sa couleur se change, sa figure se perd, sa grandeur augmente, il devient liquide, il s'échauffe, à peine le peut-on toucher, et quoiqu'on le frappe, il ne rendra plus aucun son. La même cire demeure-t-elle après ce changement? I faut avouer qu'elle demeure; et personne ne le peut nier. Qu'est-ce donc que l'on connaissait en ce morceau de cire avec tant de distinction?"1

A pergunta - o que se conhece, então, da cera com tanta distinção? - é, em última instância: o que então conheço de mim mesmo com tanta distinção? Descartes inicia sua resposta afirmando que certamente o que se conhece da cera não é o que se observa, por meio dos sentidos, já que todas aquelas coisas, tais como o gosto, o odor, a cor, o tamanho, o som, modificaram-se, sem que, contudo, a cera deixasse de ser ela mesma. Assim, descartado o conhecimento pelos sentidos, pergunta: "O que eu imagino, quando a concebo desta forma?" Conceber, conforme veremos, está vinculado aos conceitos de entender e de.compreender. Portanto, agora, tentar-se-á investigar o que é imaginação e entendimento para Descartes, tendo em vista os conceitos de concepção e de compreensão do objeto do conhecimento, no caso, a cera. Será usada além dos textos latino e francês da Segunda Meditação, a XII Regra para a Direção do Espínto, onde trata da imagjnação, entendimento, concepção e compreensão. Partiremos, contudo, da resposta de Descartes a Hobbes, o qual afirma não estar explicada na Segunda Meditação, a diferença entre imaginação e entendimento.

Respondendo à objeção de Hobbes, para quem imaginar é ter alguma idéia, e entender é concluir, raciocinando, que algo é ou existe, Descartes diz que, para imaginar um pentágono, por exemplo, "é necessária uma certa contenção do espírito, que nos torne esta figura como presente", ou seja, dê-nos uma imagem da figura. Assim, imaginamos a cera, quando formamos em nosso espírito uma imagem da cera; entretanto, não é pela imaginação que sabemos que a cera é capaz de mudar de forma, mas, sim, porque a "concebemos" capaz de semelhantes mudanças.

Na Regra XII, ao falar em imaginação, Descartes a aproxima e, parece, confundi-la com concepção: "É uma só e a mesma força [puramente espiritual] que, ao aplicar-se com a imaginação ao sentido comum, se diz: ver, tocar, etc., que, ao aplicar-se apenas à imaginação, enquanto esta se acha revestida de diversas figuras, se diz: recordar; que, ao aplicar-se a ela, para formar outras novas, se diz: imaginar ou conceber; que, finalmente, ao agir só, se diz: compreender [...]. Segundo estas diversas funções, a mesma força chama-şe ainda ou entendimento puro, ou imaginação, ou memória, ou sentidos, mas dá-se-lhe propriamente o nome de espírito, sempre que forme novas idéias na fantasia, ou se ocupe das já feitas". Note-se que, segundo este fragmento da Regra, a imaginação e o enten-

1 "Comecemos pela consideração das coisas mais comuns e que acreditamos compreender mais distintamente, a saber, os corpos que tocamos e que vemos [...]. Tomemos, por exemplo, este pedaço de cera que acaba de ser tirado da colméia: ele não perdeu ainda a doçura do mel que continha, retém ainda algo do odor das flores de que foi recolhido; sua cor, sua figura, sua grandeza, são patentes; é duro, é frio, tocamo-lo e, se nele batermos, produzirá algum som. Enfim, todas as coisas que podem distintamente fazer conhecer um corpo, encontram-se neste". Tradução J. Guinsburg e Bento Prado Júnior, col. Os Pensadores. 
dimento não têm nenhuma outra relação além da de serem ambas "funções" da força espiritual. Concipere em latim provém de cum + capere, portanto, captar num sentido mais genérico. Conceptus, derivado de concipere, realmente tem 0 sentido de concepção no plano espiritual, o qual nada mais é do que o conceito, a idéia, o verbo mental. O conceito, em Descartes, prescinde das notas individuantes da cera, forma, cor, tamanho, etc. Assim sendo, o conceito, por um lado, empobrece a realidade transcendente ou externa e, por outro lado, enobrece essa mesma realidade, porquanto eleva-a a um plano imaterial ou intencional. Com efeito, o conceito define-se como representação imaterial de objetos. Nesse sentido, aproxima-se de imaginação. De imaginan, imaginar, provém o substantivo imago, imagem, que também tem o sentido de representação, embora nem sempre imaterial.

Todavia, retornando à Segunda Meditação, imaginação e concepção não são a mesma coisa, e não devem ser confundidas. Concebe-se a capacidade da cera de mudar de forma, mas não se imagina esta capacidade, nem a infinidade de formas que a cera pode adquirir. "[...] eu não saberia mesmo conceber pela imaginação o que é esta cera, e [...] apenas meu entendimento sozinho a concebe". Assim, parece que, para se ter o entendimento do que é alguma coisa, é preciso conceber esta coisa. Porém, voltando-nos para a Regra XII, conceber e imaginar se equivalem, são a aplicação de uma função do espirito à imaginação, para formar outras imaginações. E o entendimento puro está ligado ao compreender. No entanto, na Meditação em questão, Descartes afirma que a cera só pode ser concebida pelo entendimento ou pelo espirito, o que revoga aquela afirmação da XII Regra, pois aqui concepção se desvincula da imaginação.

E o verbo conceber (concevoir), que aparece na versão francesa de 1644 ou 45 das Meditações, é a tradução do latim (versão de 1640, 41 ou 42, escrita pelo próprio Descartes) comprehendere. Comprehensio, no sentido próprio, é a ação de agarrar com as mãos; daí o sentido figurado de compreensão, percepção; conhecimento. Em Sêneca, tem também o sentido daquilo que é perceptível à vista (Sên. Nat. $6,24,1)^{2}{ }^{2}$ Descartes, ao que parece, revisou, se não toda, ao menos grande parte da tradução francesa. Assim sendo, embora a versão latina pareça mais verdadeira, porque original, talvez na versão francesa o autor se tenha permitido mudar alguma coisa das suas Meditações, ou quiçá as tenha atualizado em determinados aspectos. Porque, se tomarmos a frase: "[...] puisque je la conçois capable de recevoir une infinité de semblables changements, et je ne saurais néanmoins parcourir cette infinité par mon imagination, et par conséquent cette conception que j'ai de la cire ne s'accomplit pas par la faculté d'imaginer", ${ }^{3}$ e substituirmos conçois e conception por comprehendo e comprehensio, tal como aparece na versão latina, tendo em vista a Regra XII, poderemos ousar concluir que entendimento é compreensão, e compreensão é a ação de uma força do espirito por ela

2 FARIA, Enesto. Dicionário escolar latino-português . Rio de Janeiro: FENAME, 1975.

3 "[...] posto que a concebo capaz de receber uma infinidade de modificações similares e eu não poderia, no entanto, percorrer essa infinidade com minha imaginaçäo e, por conseguinte, essa concepção que tenho da cera não se realiza através da minha faculdade de imaginar". Tradução J. Guinsburg e Bento Prado Júnior. Col. Os Pensadores 
mesma. E que a compreensão não se dá pela faculdade de imaginação. O problema é que, considerando a versão francesa da Meditação II, contrariamente à Regra XII, a concepção de um corpo não se dá pela faculdade de imaginar. Pelo contrário, se dá pelo entendimento.

O entendimento depende de "um espírito humano" que julgue, para assim permitir compreender o que é algo. E, nesse sentido, compreender e conceber parecem corresponder-se. O exemplo dado por Descartes é de homens que passam cobertos de casacos e chapéus. Só a visão dessas figuras não me assegura que, por baixo das roupas, haja de fato homens; afinal também poderiam ser fantasmas ou autômatos. Porque julgo, ou seja, "pelo poder de julgar que reside em meu espírito", é que compreendo (comprehendo, comprends) que são homens de verdade. Assim, os termos da linguagem ordinária podem enganar, porque dizemos que vemos a cera mesma, se ela está presente, e não que nós julgamos, a partir da cor ou da figura, que ela está presente. O poder de julgar possibilita não se dejxar enganar por uma primeira percepção dos sentidos. Então Descartes considera se "concebia com mais evidência e perfeição o que era a cera, quando eu primeiro a percebi e acreditei conhecê-la por meio dos sentidos exteriores, ou, ao menos, do sentido comum, assim como eles o chamam, quer dizer, do poder imaginativo, do que eu a conheço agora, após ter mais exatamente examinado o que ela é, e de que maneira pode ser conhecida". Imaginação, aqui, é então associada aos sentidos exteriores, ou seja, à visão, ao tato. Vejo e, num primeiro momento, imagino o que é a cera. O que, contudo, não garante saber o que é efetivamente a cera, pois na imaginação ainda não foi separada daquilo que percebemos pelos sentidos, isto é, da sua cor, do seu tamanho, do seu cheiro... Assim, diz Descartes, "quando distingo a cera das suas formas exteriores, [...] e a considero toda nua, ainda que se possa encontrar algum erro no meu julgamento, eu não a posso conceber desta forma sem um espírito humano". Por outra, o entendimento despe a cera das suas características físicas para perguntar-se e tentar responder o que é de fato a cera em si, vale dizer, aquilo que de duro passa a mole, quando se derrete e que pode ter variadas cores e formas. E, deste modo, permite conceber e compreender o que é a cera. É mister notar que se falou em compreender pelo poder de julgar, que reside no espírito, e conceber, quando se percebeu, pelos sentidos, num primeiro momento a cera. A seguir, fala-se em conhecer a cera, após tê-la examinado mais atentamente. Assim, parece que conceber, segundo a versão francesa, tanto serve para aquilo que se percebe pelos sentidos, como para aquilo que se tenta conhecer pelo entendimento, pois é necessário lembrar que a diferença entre imaginação e entendimento é tratada, tendo em vista a busca pelo conhecimento do que eu sou.

$E$ então, subitamente, pergunta: "O que diria eu deste espírito, quer dizer, de mim mesmo?" Volta, pois, à questão do conhecimento de si, que procura solucionar, através da tentativa de conhecer a cera. "O que diria eu deste espírito, quer dizer, de mim mesmo?" Volta, pois, à questão do conhecimento de si, que procura solucionar, através da tentativa de conhecer a cera. "O que afirmaria eu, digo, de mim, que pareço conceber com tanta nitidez e distinção este pedaço de cera?" O conhecimento da cera assegura a existência daquele que a conhece. Seja porque a 
vê, ou porque pensa vê-la, ou porque a toca, ou julga, ou por aquilo de que sua imaginação o persuade, ou por qualquer outra causa que seja. $O$ fato é que conclui sempre a mesma coisa: "eu existo", e termina a meditação com as seguintes palavras: "[...] nós só conhecemos os corpos pela faculdade de entender que está em nós, e não absolutamente pela imaginação, nem pelos sentidos [...]; [só conhecemos] o que nós concebemos pelo pensamento, eu conheço evidentemente que não há nada que me seja mais fácil de conhecer que o meu espírito".

\section{Referências bibliográficas}

DESCARTES, René. Méditations métaphysiques, objections et réponses suivies de quatre lettres.

(Versão bilingüe latim/francês das Méditations). Paris: Garnier-Flammarion, 1979. . Regras para a direcção do espíito. Lisboa: Edições 70, 1989.

FARIA, Emesto. Dicionánio escolar latino-português. Rio de Janeiro: FENAME, 1975. 